\title{
High expression of MAGE-A9 contributes to stemness and malignancy of human hepatocellular carcinoma
}

\author{
YOUPING WEI $^{1 *}$, YANQIN WANG $^{1 *}$, JING GONG $^{1 *}$, LIHUA RAO $^{1}$, \\ ZHIWEI WU ${ }^{1}$, TENG NIE ${ }^{1}$, DONGLING SHI ${ }^{1}$ and LIMING ZHANG ${ }^{1,2}$ \\ ${ }^{1}$ Affiliated Hospital of Integrated Traditional Chinese and Western Medicine, Jiangxi University \\ of Traditional Chinese Medicine, Nanchang, Jiangxi 330003; ${ }^{2}$ Medical Laboratory, Taizhou \\ Central Hospital (Taizhou University Hospital), Taizhou, Zhejiang 318000, P.R. China
}

Received August 14, 2017; Accepted October 23, 2017

DOI: 10.3892/ijo.2017.4198

\begin{abstract}
MAGE-A9, a well-characterized cancer testis antigen (CTA), belongs to a member of melanoma antigen gene (MAGE) family. In human malignancies, aberrant expression of MAGE genes correlated with poor clinical prognosis, increased tumor growth, metastases, and enrichment in stem cell populations of certain cancers. Cancer stem cells (CSCs) have been proposed to contribute to the major malignant phenotypes of liver cancer, including recurrence, metastasis and chemoresistance. However, expression and potential role of MAGE-A9 in liver cancer stem cells (LCSCs) still remain unclear. In the present study, we first analyzed the expression profiling of MAGE family genes in $\mathrm{EpCAM}^{+}$and EpCAM human hepatocellular carcinoma (HCC), based on public Gene Expression Omnibus (GEO) database. Among these examined MAGE members, MAGE-A9 is the only one with significantly higher expression in $\mathrm{EpCAM}^{+} \mathrm{HCC}$ specimens as compared with EpCAM- HCC. Quantitative PCR analysis further confirmed that MAGE-A9 expression significantly elevated in a subtype of HCC patients that had features of hepatic stem/progenitor cells with high-level expression of EpCAM and $\alpha$-fetoprotein (AFP). Moreover, MAGE-A9 displayed remarkably enriched expression in $\mathrm{EpCAM}^{+} \mathrm{HCC}$ cells that were sorted by fluorescence-activated cell sorting and cultured HCC cell spheroids with characteristics of stem/ progenitor cells. Functional experiments further revealed that MAGE-A9 overexpression promoted cell proliferation, colony formation, migration, chemoresistance, and tumorigenicity
\end{abstract}

Correspondence to: Dr Liming Zhang, Affiliated Hospital of Integrated Traditional Chinese and Western Medicine, Jiangxi University of Traditional Chinese Medicine, No. 90 Bayi Road, Xihu, Nanchang, Jiangxi 330003, P.R. China

E-mail: zxyyzlm@163.com

${ }^{*}$ Contributed equally

Key words: MAGE-A9, hepatocellular carcinoma, cancer testis antigen, liver cancer stem cells, spheroid culture, chemoresistance, therapeutic target in the context of $\mathrm{EpCAM}^{+} \mathrm{HCC}$ cells, whereas MAGE-A9 knockdown significantly inhibited anchorage-dependent and spheroid colony formation and in vivo tumorigenicity. Collectively, these data demonstrate that MAGE-A9 functions as an important regulator of LCSCs, and MAGE-A9 may serve as a potential therapeutic target against $\mathrm{HCC}$ stem/progenitor cells.

\section{Introduction}

Hepatocellular carcinoma (HCC), accounting for $90 \%$ of liver cancers, is an often fatal malignancy with a high recurrence and chemoresistance in the world (1). To date, there are few therapeutic approaches for advance cases except for surgical resection. In the past few decades, cancer stem cells (CSCs) in liver cancer has been identified and proposed to be responsible for major malignant phenotypes including tumor growth, metastasis, recurrence and chemoresistance. Therefore, liver cancer stem cells (LCSCs) are considered an important targeting subset to improve the curative effect of treatments $(2,3)$. LCSCs could be identified by several markers, including CD133, CD90, CD44, EpCAM and CD13 (4,5). Among these LCSCs biomarkers, epithelial cell adhesion molecule (EpCAM) is frequently and highly expressed on carcinomas, tumor-initiating cells, selected tissue progenitors and embryonic and adult stem cells (6). $\mathrm{EpCAM}^{+} \mathrm{HCC}$ displayed a distinct molecular signature with features of hepatic progenitor cells and showed hepatic cancer stem celllike traits, including self-renewal and differentiation and were highly invasive and tumorigenic (7).

Cancer/testis antigens (CTAs) are a family of genes with common expression characteristics: they are normally expressed only in human germ line, but are also expressed in a variety of tumors types (8). Recently, it was reported that some CTAs such as CTAG1B, MAGE-1 and SSX are expressed in human mesenchymal stem cells (MSCs), suggesting that CTAs may be a stem cell marker $(9,10)$. Multiple CTAs, such as LUZP4 and ODF1, have unique expression profiles in multiple myeloma (MM) stem cells (11). MAGE-A3 has much higher expression in a cancer stem cell-like side population in bladder cancer (12). Additionally, considerable numbers of CT genes had preferential expression in the stem cell-like side population 
of multiple cancer cell lines (13). More importantly, the function of CTAs has been involved in stem cell biology. For instance, SSX is involved in self-renewal and differentiation of stem cells, as supported by several investigations $(9,14)$.

The melanoma antigen gene (MAGE) family represents one of the largest groups of human tumor-associated antigens and are well-characterized members of the cancer/testis antigen. MAGE family has gained increasing interest as biomarkers in cancer and targets of immunotherapies because a subset of these $>40$ human proteins are classified as CTAs (15). Members of human MAGE family can be divided into two categories based on tissue expression pattern: type I MAGEs, including MAGE-A, -B and -C subfamily members which are clustered on the $\mathrm{X}$ chromosome, are considered CTAs; type $\Pi$ MAGEs (MAGE-D, -E, -F, -G, -H, -L subfamilies and Necdin) are expressed throughout many tissues in the body and are not restricted to the $\mathrm{X}$ chromosome (15). MAGEs have been found to be broadly expressed in many tumor types, and their re-expression are associated with hallmarks of aggressive cancers. Importantly, functional studies have demonstrated that some MAGE CTAs can have non-overlapping oncogenic driver activity.

We focused our attention on MAGE CTAs (type I) and globally analyzed their expression profile in a set of public microarray data from $\mathrm{EpCAM}^{+}$and $\mathrm{EpCAM}^{-} \mathrm{HCC}$ patients (16). Notably, we found that MAGE-A9, a MAGEA family member, was the only one with significant enrichment expression in $\mathrm{EpCAM}^{+} \mathrm{HCC}$ samples, strongly suggesting MAGE-A9 could be a potential LCSCs biomarker. MAGE-A9, a member of MAGE-A gene family, is frequently expressed in a variety of human tumors, such as bladder $(17,18)$, breast $(19,20)$, non-small cell lung cancer (21), laryngeal squamous cell carcinoma (22) and renal cell carcinoma (23) and hepatocellular carcinoma (24). Furthermore, clinical and functional studies showed that MAGE-A9 expression could provide prognostic information and be a potential therapeutic target (21-23,25). However, the role of MAGE-A9 is still largely unknown in HCC, especially liver cancer stem cells. In the present study, we found that MAGE-A9 had higher expression in a subtype of HCC with stem/progenitor cell-like features. The following functional experiments showed that MAGE-A9 indeed contributed to malignant biological phenotypes of HCC cells, including cell proliferation, migration and chemoresistance in the context of $\mathrm{EpCAM}^{+} \mathrm{HCC}$ cells. Collectively, MAGE-A9 can modulate liver cancer stem cell-like characteristics and may be a potential target for LCSCs therapy.

\section{Materials and methods}

Cell lines and tissue specimens. The liver tumor-derived cell lines included PLC/PRF/5, Sk-hep-1, MHCC97, Hep3B and Huh-7 were obtained from the Cell Bank of Chinese Academy of Sciences in Shanghai. These cell lines were grown in Dulbecco's modified Eagle's medium (DMEM) supplemented with 10\% fetal bovine serum (FBS; Life Technologies, Carlsbad, CA, USA) and penicillin (100 U/ml $) /$ streptomycin sulfate $(100 \mu \mathrm{g} / \mathrm{ml})$ (Invitrogen, Carlsbad, CA, USA). Cells were cultured at $37^{\circ} \mathrm{C}$ in $5 \% \mathrm{CO}_{2}$ humidified incubator. Cell line authentication was performed by short tandem repeats (STRs) profiling before this study. Liver cancer samples were obtained with informed consent from each HCC patients who underwent curative resection.

Immunohistochemical analysis. A commercial tissue microarray (TMA) from Shanghai Outdo Biotech Co., Ltd. (SOBC; Shanghai, China) is comprised of 90 paired formalin-fixed paraffin-embedded (FFPE) tissues from HCC patients. The original clinical data of the TMA include patient sex, age, tumor size, the 7th edition AJCC TNM stage, tumor grade, histological type, lymph node metastasis status, OS time and survival status. IHC staining was performed as previously described $(19,26)$. Briefly, the TMA sections (4 $\mu$ m thickness) were deparaffinized and rehydrated by passage through xylene and a graded alcohol series. Antigen retrieval was performed using heat-mediated microwave methods and antigen unmasking solution (Vector Laboratories, Burlingame, CA, USA). Then, these tissue samples were naturally cooled to room temperature (RT) and incubated with $0.3 \% \mathrm{H}_{2} \mathrm{O}_{2}$ for $10 \mathrm{~min}$ to inactivate endogenous peroxidase activity. TMA sections were incubated with a primary monoclonal mouse anti-MAGE-A9 antibody (1:200; Abcam) and then by peroxidase-conjugated secondary antibody. Negative controls were included by replacement of the primary antibody with phosphate-buffered saline (PBS). The reaction product was detected by ABC and DAB kit (Vector Laboratories) and counterstained with hematoxylin. Two experienced pathologists without any knowledge of the clinicopathological information independently evaluated the result of MAGE-A9 immunoreactivity. A semi-quantitative scoring system (0-3) was used to evaluate the expression level of MAGE-A9 as previously described (24). The intensity of the staining was classified as negative, weak, moderate or strong. Staining intensity was scored as follows: 0 (negative), 1 (weakly positive), 2 (moderately positive) and 3 (strongly positive). The percentage of MAGE-A9-positive cells was also scored according to 4 categories, where 1 was for $0-10 \%, 2$ for $11-50 \%, 3$ for $51-80 \%$ and 4 for $81-100 \%$. The product of the intensity and percentage scores was used as the final MAGE-A9 staining score. The degree of MAGE-A9 staining was quantified using a two-level grading system as follows: $<3$ indicates low or no expression while 3-9 indicates high expression.

Cell viability assay and colony formation assay. For cell growth analysis, cells were plated on 96-well plates at a density of $2 \times 10^{3}$ cells/well, and cell viability was measured using the Cell Counting kit-8 (CCK-8; Dojindo Laboratories, Kumamoto, Japan) according to the manufacturer's instructions. Briefly, $10 \mu 1$ of CCK-8 solution was added to each well, incubated with cells at $37^{\circ} \mathrm{C}$ for $1 \mathrm{~h}$. Absorbance value was measured at $450 \mathrm{~nm}$ for 5 days. For chemoresistance tests, cells were plated on 96-well plates at a density of $1 \times 10^{4}$ cells/well. When cells were $90 \%$ confluent, they were treated with doxorubicin (Sigma-Aldrich, St. Louis, MO, USA) and cisplatin (Alexis Biochemicals, Lausen Switzerland) for $72 \mathrm{~h}$, and cell viability was measured using the CCK-8 method. For anchorage-dependent colony formation assay, $\mathrm{HCC}$ cells were plated at a density of $2 \times 10^{3}$ to $5 \times 10^{3}$ cells/plate in $100-\mathrm{mm}$ plates. Three weeks later, forming colony were washed with PBS twice and then stained with crystal violet. Anchorageindependent colony formation was performed in 6-well plates, 
Table I. Primers sequences used in the present study.

\begin{tabular}{|c|c|c|}
\hline Gene & mRNA Ref & Primer sequence \\
\hline \multirow[t]{2}{*}{ MAGE-A9 } & NM_005365 & Forward: 5'-CTGGGGGTCAGAGAGAAGG-3' \\
\hline & & Reverse: 5'-CTCTGCGACCTGAGGACACT-3' \\
\hline \multirow[t]{2}{*}{ AFP } & NM_001134 & Forward: 5'-AGAGGAGATGTGCTGGATTG-3' \\
\hline & & Reverse: 5'-GTGGTCAGTTTGCAGCATTC-3' \\
\hline \multirow[t]{2}{*}{ EPCAM } & NM_002354 & Forward: 5'-CTGAATTCTCAATGCAGGGTC-3' \\
\hline & & Reverse: 5'-CCCATCTCCTTTATCTCAGCC-3' \\
\hline \multirow[t]{2}{*}{ KRT18 } & NM_199187 & Forward: 5'-GGGAGCACTTGGAGAAGAAG-3' \\
\hline & & Reverse: 5'-CGGGCATTGTCCACAGTATT-3' \\
\hline \multirow[t]{2}{*}{ ALB } & NM_000477 & Forward: 5'-TGCTGATGAGTCAGCTGAAAA-3 \\
\hline & & Reverse: 5'-TCAGCCATTTCACCATAGGTT-3' \\
\hline \multirow[t]{2}{*}{ GAPDH } & NM_002046 & Forward: 5'-GAAGGTGAAGGTCGGAGTCA-3' \\
\hline & & Reverse: 5'-TTGAGGTCAATGAAGGGGTC-3' \\
\hline
\end{tabular}

where cells were grown on $1 \%$ base agar and $0.3 \%$ top agar medium for 3 weeks. Colonies were stained with crystal violet and counted. All experiments were independently repeated 3 times.

$R N A$ isolation and quantitative reverse transcription PCR (qRT-PCR). Total RNA was prepared using TRIzol reagent (Life Technologies), as described by the manufacturer's protocol. One microgram of total RNA was reverse transcribed with iScript ${ }^{\mathrm{TM}}$ gDNA Clear cDNA Synthesis kit (Bio-Rad Laboratories, Hercules, CA, USA). Quantitative real-time reverse transcription PCR was performed using iTaq $^{\mathrm{TM}}$ Universal SYBR ${ }^{\circledR}$ Green Supermix (Bio-Rad Laboratories). GAPDH was used as an internal control. All the primer sequences were listed in Table I.

Flow cytometric analysis. FITC-conjugated EpCAM monoclonal antibody (EBA-1; Santa Cruz Biotechnology, Santa Cruz, CA, USA) was used to sort EpCAM ${ }^{+}$cells from Hep3B and $\mathrm{HuH}-7$ cells. Cultured HCC cells were dissociated with $0.25 \%$ trypsin-EDTA $(1 \mathrm{mM})$ for $3 \mathrm{~min}$, and washed with fluorescence-activated cell sorting buffer [PBS containing $1 \%$ fetal calf serum (FCS)] and then incubated for $1 \mathrm{~h}$ at $4^{\circ} \mathrm{C}$ in fluorescence-activated cell sorting buffer with anti-EpCAM antibody. Flow cytometric analysis was performed using a FACSCalibur or FACSAriaII (BD Biosciences, San Jose, CA, USA).

Transwell migration assay. Twenty-four-well, $8.0 \mu \mathrm{m}$ was used to perform Transwell assay. HCC cells were starved in serumfree medium for $8 \mathrm{~h}$. These cells were seeded in the upper chamber with low-serum (1\% FBS) medium, while highserum (10\% FBS) medium was placed in the lower chamber. Following an incubation period, the permeable cells were stained and photographed. Stained cells were counted using ImageJ software.

Spheroid colony formation assay. Cells were seeded at a density of 1,000 cells $/ \mathrm{ml}$ in the ultra-low attachment plate (Corning Costar, Corning, NY, USA) in DMEM/Nutrient Mixture F-12
Ham (Sigma-Aldrich) supplemented with recombinant human basic fibroblast growth factor $(20 \mathrm{ng} / \mathrm{ml}), \mathrm{B}-27$, recombinant human epidermal growth factor $(20 \mathrm{ng} / \mathrm{ml})$, L-glutamine (200 mmol/l). Spheroids were observed and counted using inverted microscope operated with a Nikon Ds-Fi1 camera and NIS Elements software (Nikon, Tokyo, Japan).

Plasmid construction, lentivirus production and transfection. Human MAGE-A9 coding sequence was cloned into lentivirus vector pLenti vector. For MAGE-A9 knockdown, two shRNA oligos against MAGE-A9 gene were designed and these target sequences against MAGE-A9 is as follows: A9-sh1, 5'-CAT GCA GGT GAT CTT TGG CAC TGA T-3'; A9-sh2, 5'-AAT TGA AGG TGG CTG AGT TGG TT-3'. A scrambled shRNA control with sequence (5'-AAC AGT CGC GTT TGC GAC TGG-3') that does not match any known mammalian GenBank sequence was used as a negative control. The shRNA oligos were reannealed, and then cloned into lentivirus vector pLKO.1-TRC cloning vector. Lentivirus were generated by transfecting lentivirus vectors with MAGE-A9 overexpression or knockdown together with packaging vector psPAX2 and pMD2.G into 293T cells. Polybrene (Sigma-Aldrich) at the concentration of $8 \mu \mathrm{g} / \mathrm{ml}$ was added to enhance the infection. Blasticidin $(0.5 \mu \mathrm{g} / \mathrm{ml})$ and puromycin $(1 \mu \mathrm{g} / \mathrm{ml})$ were used to screen the stable infected cells.

Western blotting assay. HCC cells were harvested after washing twice with ice-cold PBS. Protein was extracted by RIPA Lysis and Extraction Buffer (Thermo Fisher Scientific, Waltham, MA, USA). The protein concentration was measured using a BCA protein assay kit (Thermo Fisher Scientific/Pierce). The same amounts of protein lysates were boiled at $95^{\circ} \mathrm{C}$ after adding Laemmli protein sample buffer (Bio-Rad Laboratories). Samples were separated on 4-12\% SDS-polyacrylamide gels and transferred to a nitrocellulose membrane (Life Technologies). The membranes were blocked with $5 \%$ BSA for $1 \mathrm{~h}$ at room temperature and incubated with primary at $4^{\circ} \mathrm{C}$ overnight. Primary antibodies used in the present study were MAGE-A9, GAPDH and ALB antibody from Santa Cruz Biotechnology, OCT4, SOX2 and NANOG 
Table II. Expression analysis of MAEG genes in HCC samples.

\begin{tabular}{|c|c|c|c|c|c|}
\hline Gene symbol & mRNA RefSeq & $\mathrm{EpCAM}^{+} \mathrm{HCC}(\mathrm{n}=95)$ & $\mathrm{EpCAM}^{-} \mathrm{HCC}(\mathrm{n}=143)$ & Difference between means & P-value \\
\hline MAGE-A1 & NM_004988 & $0.240 \pm 0.221$ & $1.162 \pm 0.190$ & $-0.922 \pm 0.294$ & 0.001 \\
\hline MAGE-A5 & NM_021049 & $-0.391 \pm 0.097$ & $-0.212 \pm 0.078$ & $-0.179 \pm 0.124$ & 0.075 \\
\hline MAGE-A8 & NM_005364 & $-0.514 \pm 0.167$ & $0.102 \pm 0.121$ & $-0.616 \pm 0.201$ & 0.001 \\
\hline MAGE-A9 & NM_005365 & $0.546 \pm 0.064$ & $0.404 \pm 0.054$ & $0.142 \pm 0.084$ & 0.047 \\
\hline MAGE-A10 & NM_021048 & $-1.473 \pm 0.131$ & $-0.996 \pm 0.093$ & $-0.478 \pm 0.157$ & 0.001 \\
\hline MAGE-A11 & NM_005366 & $-1.127 \pm 0.117$ & $-0.940 \pm 0.101$ & $-0.187 \pm 0.157$ & 0.117 \\
\hline MAGE-A12 & NM_005367 & $-0.016 \pm 0.263$ & $0.945 \pm 0.242$ & $-0.961 \pm 0.366$ & 0.005 \\
\hline MAGE-B1 & NM_002363 & $-1.992 \pm 0.144$ & $-1.763 \pm 0.159$ & $-0.230 \pm 0.227$ & 0.157 \\
\hline MAGE-B2 & NM_002364 & $-0.837 \pm 0.206$ & $-0.518 \pm 0.139$ & $-0.319 \pm 0.239$ & 0.092 \\
\hline MAGE-B3 & NM_002365 & $-1.382 \pm 0.113$ & $-1.178 \pm 0.101$ & $-0.203 \pm 0.154$ & 0.094 \\
\hline MAGE-B4 & NM_002367 & $-0.919 \pm 0.192$ & $-0.956 \pm 0.176$ & $0.036 \pm 0.266$ & 0.446 \\
\hline MAGE-B10 & NM_182506 & $-1.434 \pm 0.138$ & $-1.189 \pm 0.143$ & $-0.244 \pm 0.208$ & 0.121 \\
\hline MAGE-B18 & NM_173699 & $-0.599 \pm 0.068$ & $-0.422 \pm 0.065$ & $-0.177 \pm 0.097$ & 0.036 \\
\hline
\end{tabular}

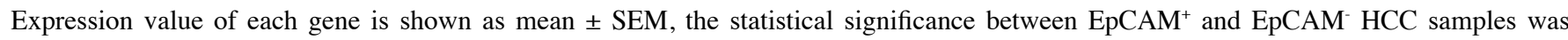
determined by one-tailed unpaired t-test.

from Cell Signaling Technology (Danvers, MA, USA). Peroxidase-conjugated secondary antibodies were used, membranes were developed using the enhanced chemiluminescent immunoassay for the detection of antigen.

Tumorigenicity in mice. HCC cells were mixed with an equal volume of Matrigel, and then subcutaneously injected into the flank of male NOD/SCID mice, 4-5 weeks old. Tumor dimensions were measured twice a week using a digital caliper and the tumor volume was calculated by the formula: $\mathrm{V}=0.5 \mathrm{x}$ width $^{2} \mathrm{x}$ length. The mice were sacrificed by $\mathrm{CO}_{2}$ euthanasia. Kaplan-Meier method was used to analyze tumor-free survival rate, and the statistical significance was determined using the log-rank test. P-values that were $<0.05$ were considered statistical significant. All mice were housed in pathogen-free animal facilities and handled in accordance with the guidelines of the Institutional Animal Care and Use Committee at the Affiliated Hospital of Integrated Traditional Chinese and Western Medicine, Jiangxi University of Traditional Chinese Medicine. All animal procedures were conducted in compliance with institutional guidelines and protocols.

Statistical analysis. Gene expression data were obtained from the National Center for Biotechnology Information Gene Expression Omnibus database (GEO accession number GSE5975), as previously published (16). The differences between the two groups in gene expression, cell proliferation, colony number, and permeable cells number were calculated using the Student's t-test. The significance of MAGE-A9 protein expression on clinical parameters of HCC was determined by Chi-square test. Kaplan-Meier survival analysis was also employed to explore the associations between the MAGE-A9 expression and the outcome of HCC patients. For all tests, the significant level for statistical analysis was set at $\mathrm{P}<0.05$. All the statistical analyses were conducted by using the GraphPad Prism software 6.0 (GraphPad Software, Inc., San Diego, CA, USA).

\section{Results}

High expression of MAGE-A9 in EpCAM+ HCC patients. We first analyzed the expression profiling of type I MAGE family members based on a public microarray dataset deposited in Gene Expression Omnibus (GEO) database. In the dataset, gene expression profiling was established on tumor tissues from 238 HCC patients, which were categorized into $\mathrm{EpCAM}^{+}$ $(n=95)$ and EpCAM $^{-}(n=143)$ subgroups according to EpCAM, a marker for cancer stem cells in hepatocellular carcinoma. We compared the expression difference of MAGE members between $\mathrm{EpCAM}^{+}$and EpCAM ${ }^{-}$HCCs. Of 13 MAGE genes available in the database, 6 genes exhibit significant differences between the two groups (Fig. 1A and Table II). Notably, only MAGE-A9 had higher expression in EpCAM ${ }^{+}$HCCs, whereas MAGE-A1, MAGE-A8, MAGE-A10, MAGE-A12 and MAGE-B18 had lower expression in EpCAM ${ }^{+}$HCCs compared with EpCAM- HCCs (Fig. 1B). Because a previous study proposed that $\mathrm{EpCAM}^{+} / \mathrm{AFP}^{+} \mathrm{HCC}$ subtype resembling liver stem/progenitors cells was characterized by a highly invasive nature, chemoresistance to cytotoxic reagents, and a worse prognosis (27). To evaluate the MAGE-A9 expression in liver stem/progenitors, we performed real-time qPCR to examine the expression of MAGE-A9, EpCAM and AFP in another different cohort of 61 HCC samples stored in liquid nitrogen. According to EpCAM and AFP expression level, we divided these $\mathrm{HCC}$ samples into $\mathrm{EpCAM}^{+} / \mathrm{AFP}^{+}$ HCCs group $\left(\Delta c t^{\text {EpCAM-GAPDH }}<5\right.$ and $\left.\Delta c \mathrm{t}^{\text {AFP-GAPDH }}<5, \mathrm{n}=10\right)$ and non-EpCAM ${ }^{+} / \mathrm{AFP}^{+} \mathrm{HCCs}$ group $\left(\Delta \mathrm{ct}^{\mathrm{EpCAM}-\mathrm{GAPDH}}>5\right.$ or $\Delta \mathrm{ct}^{\mathrm{AFP}-\mathrm{GAPDH}}>5, \mathrm{n}=51$ ) (Fig. $1 \mathrm{C}$ ). Further analysis showed that MAGE-A9 had significant enriched expression in $\mathrm{EpCAM}^{+} / \mathrm{AFP}^{+} \mathrm{HCCs}$ in comparison with non-EpCAM ${ }^{+} / \mathrm{AFP}^{+}$ HCCs $(\mathrm{P}=0.002)$ (Fig. 1D) 

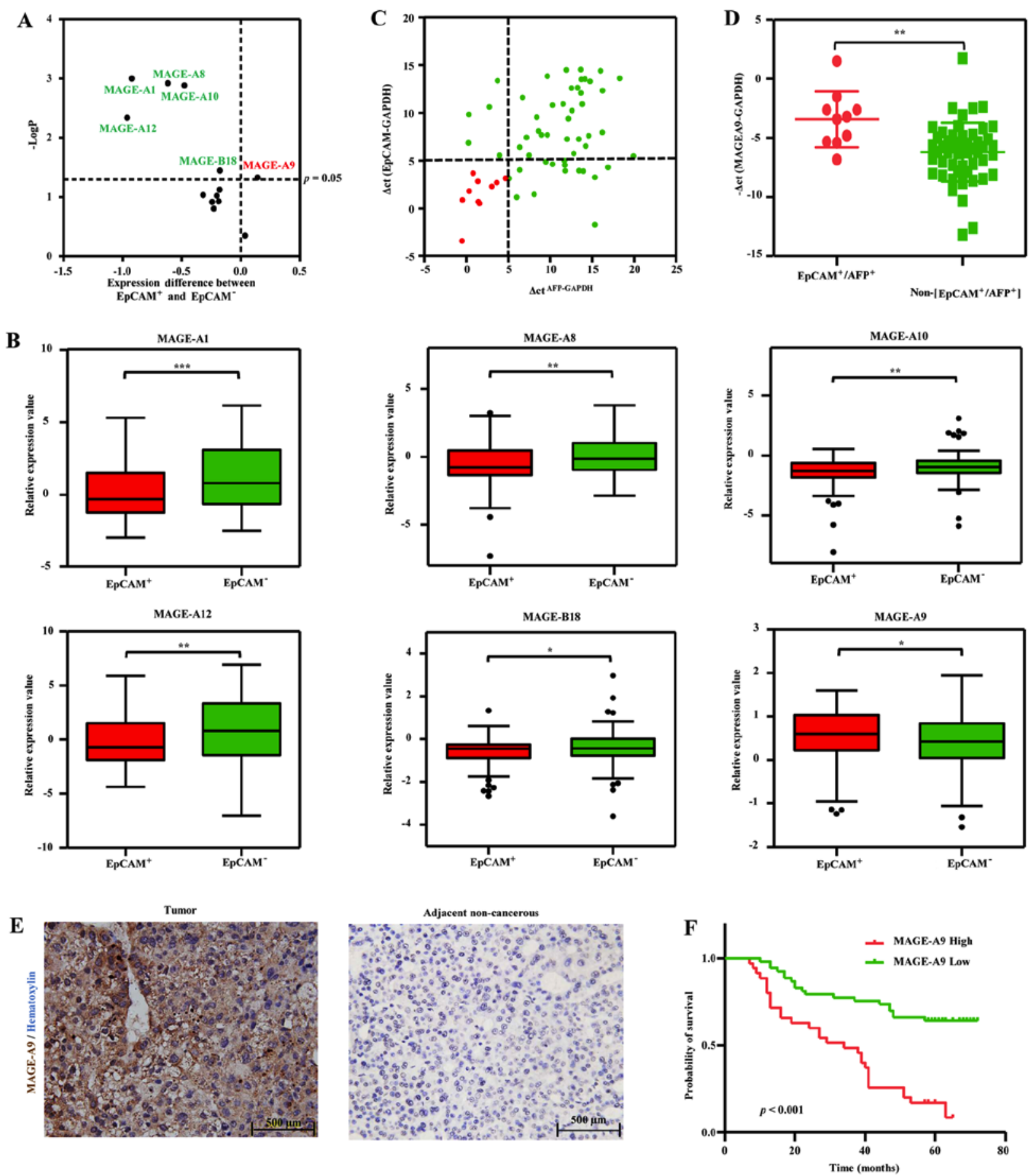

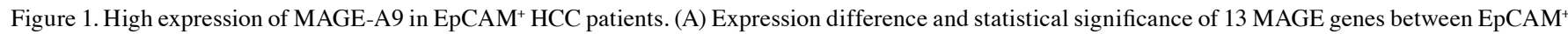
HCCs $(n=95)$ and EpCAM HCCs $(n=143)$. $P<0.05$ or $-\log ^{\mathrm{p}}>1.301$ was considered to be significant. (B) Expression profiling of MAGE-A1, MAGE-A8,

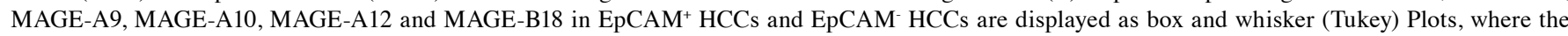
dots at the end of the boxplot represent outliers. (C) Quantitative real-time polymerase chain reaction (qPCR) was carried out to measure the expression level of EpCAM and AFP in $61 \mathrm{HCC}$ tumors, where relative gene expression level was normalized to the GAPDH internal control. According to the relative expression value of EpCAM and AFP, $10 \mathrm{EpCAM}^{+} / \mathrm{AFP}^{+} \mathrm{HCC}$ samples were demarcated at the region with EpCAM-high expression $\left(\Delta \mathrm{ct}^{\mathrm{EPCAM}-\mathrm{GAPDH}}<5\right)$ and AFP-high expression $\left(\triangle \mathrm{ct}^{\mathrm{AFP}-\mathrm{GAPDH}}<5\right)$, shown as red points. Remaining $51 \mathrm{HCC}$ tumors, shown as green points, belong to non-(EpCAM $\left.{ }^{+} / \mathrm{AFP}^{+}\right) \mathrm{HCCs}$. (D) Real-time qPCR analysis of MAGE-A9 in $\mathrm{EpCAM}^{+} / \mathrm{AFP}^{+} \mathrm{HCCs}(\mathrm{n}=10)$ and non- $\left(\mathrm{EpCAM}^{+} / \mathrm{AFP}^{+}\right) \mathrm{HCCs}(\mathrm{n}=51)$ was shown in the scatter plot, where the dots indicate $-\Delta \mathrm{Ct}^{\mathrm{MAGE}-\mathrm{A} 9 \text {-GAPDH }}$ value, and the lines represent the mean $\pm \mathrm{SD}$ value, respectively. Statistical significance was determined by two-tailed t-test. ${ }^{* *} \mathrm{P}<0.01$ (E) Immunohistochemical analysis of MAGE-A9 in HCCs. Representative photomicrographs of MAGE-A9 high expression (left panel) in tumor tissue and MAGE-A9 low expression (right panel) in non-cancerous liver are shown (scale bar, $500 \mu \mathrm{m}$ ). (F) Kaplan-Meier survival curves for $90 \mathrm{HCC}$ patients. MAGE-A9 high HCCs $(n=40)$ presented a poor prognosis compared with those HCCs with low MAGE-A9 expression $(n=50)$.

To confirm MAGE-A9 protein expression in HCC, immunohistochemical staining using MAGE-A9 antibody was carried out on a tissue array loaded with a different group of 90 paired FFPE samples, including HCC tissues and their adjacent non-cancerous tissues. Expectedly, high MAGE-A9 expression levels was observed in 40 of 90 (44\%) HCC tissue 
A
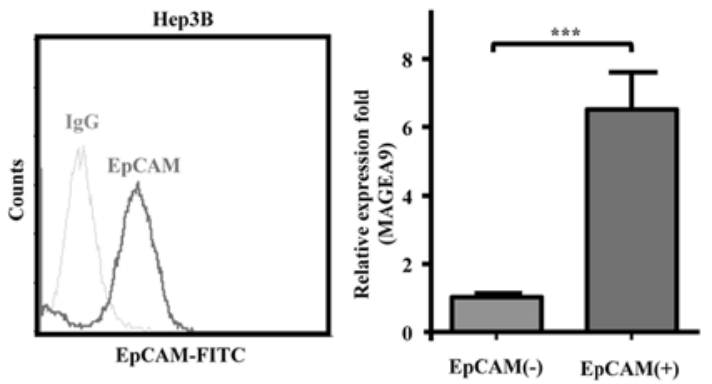

C
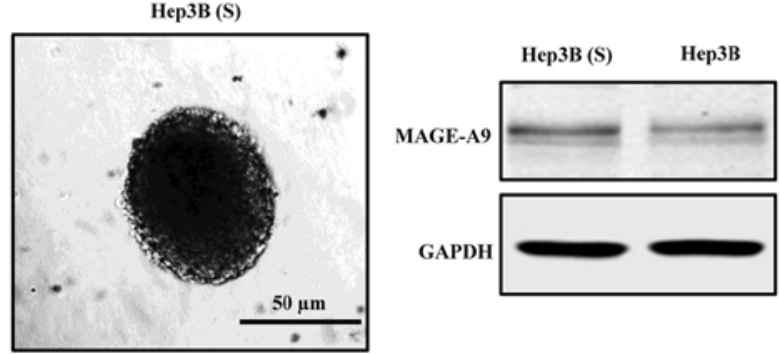

B
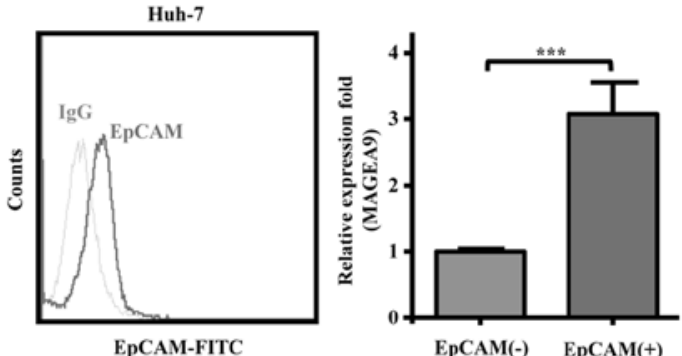

D

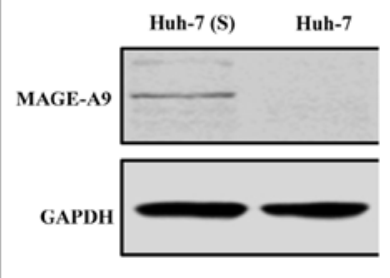

$\mathbf{E}$

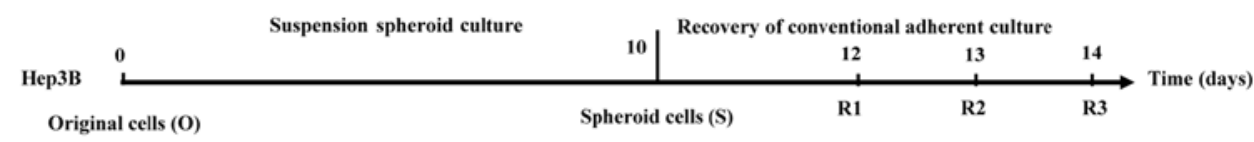

$\mathbf{F}$
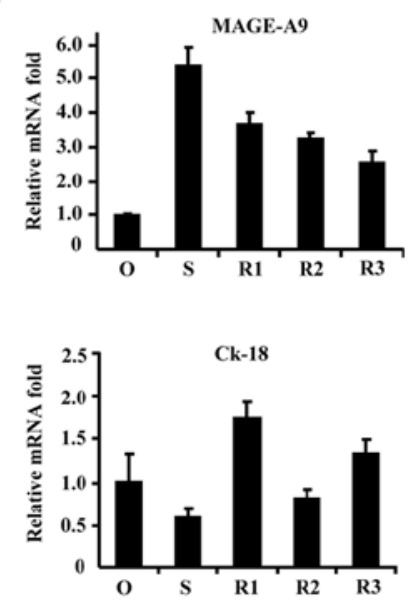
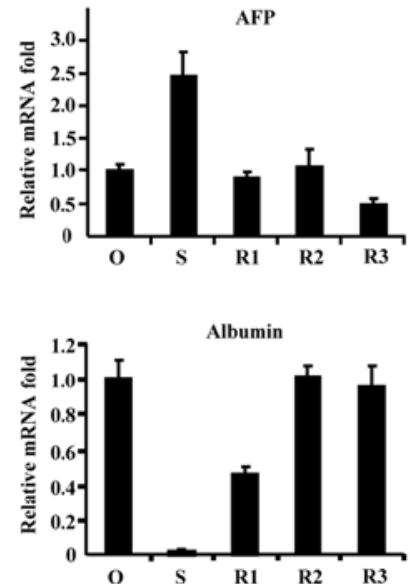

G

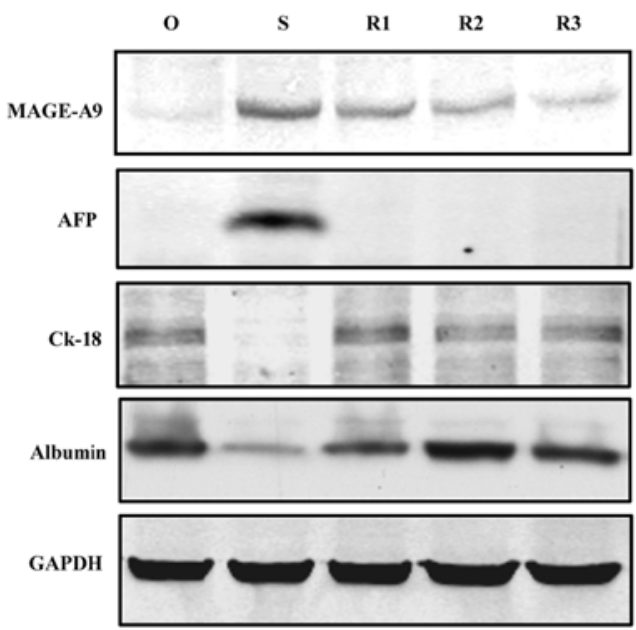

Figure 2. Enriched MAGE-A9 expression in $\mathrm{EpCAM}^{+} \mathrm{HCC}$ cells and spheroid colonies. (A) Quantitative reverse transcription-polymerase chain reaction (qRT-PCR) analysis of MAGE-A9 in EpCAM ${ }^{+}$and EpCAM- Hep3B cells, which were isolated by FACS sorting. (B) EpCAM ${ }^{+}$and EpCAM-Huh-7 cells were sorted by flow cytometry, and qRT-PCR examined the MAGE-A9 expression. (C and D) Spheroid colonies, shown in left panel, were derived from Hep3B (C) and Huh-7 (D) cells cultured in serum-free medium, and MAGE-A9 protein was detected by western blot assay (right panel) in parent and spheroid cells. (E) Original Hep3B cells $(\mathrm{O})$ were subject to spheroid culture in ultralow attachment plates for 10 days until these spheroid colonies (S) were produced. Then the spheroid colonies were reverted to the previous conventional adherent culture way for 3 days (R1, R2 and R3). (F) qRT-PCR analysis of the relative mRNA levels of MAGE-A9, AFP, Ck-18 and ALB in different culture times. (G) Western blotting assay was performed to evaluate the expression of MAGE-A9, AFP, Ck-18 and ALB. GAPDH was used as an internal reference.

samples, consistent with a previous report (24). There was significant difference in high expression rate of MAGE-A9 protein between $\mathrm{HCC}$ tissues and non-cancerous tissues $(\mathrm{P}=0.005)$. As shown in Fig. 1E, MAGE-A9 protein was primarily localized in the cytoplasm of HCC cells. MAGE-A9 protein high expression was significantly correlated with tumor size $(\mathrm{P}=0.011)$ and recurrence $(\mathrm{P}=0.009)$, whereas there were no significant associations between MAGE-A9 protein expression level and other clinical features, including sex, age, cirrhosis, HBV, HCV, pathological grade and AFP status. The association between MAGE-A9 protein expression and clinicopathological parameters is summarized in Table III. MAGE-A9-low HCCs showed better survival than HCCs with MAGE-A9-high expression, and significantly MAGE-A9high HCCs exhibited a worse prognosis than MAGE-A9 low HCCs $(\mathrm{P}<0.001$; Fig. 1F). Overall, our analyses suggest that 
Table III. Relationship of high MAGE-A9 expression with clinicopathological characteristics in HCCs.

\begin{tabular}{|c|c|c|c|}
\hline Parameters & $\begin{array}{c}\text { MAGE-A9- } \\
\text { high } \\
(n=40)\end{array}$ & $\begin{array}{c}\text { MAGE-A9- } \\
\text { low } \\
(n=50)\end{array}$ & $\mathrm{P}$-value \\
\hline Sex & & & 1.000 \\
\hline Male & 33 & 41 & \\
\hline Female & 7 & 9 & \\
\hline Age (years) & & & 0.328 \\
\hline$<60$ & 28 & 40 & \\
\hline$\geq 60$ & 12 & 10 & \\
\hline Cirrhosis & & & 0.145 \\
\hline Positive (+) & 37 & 41 & \\
\hline Negative (-) & 3 & 9 & \\
\hline HBsAg & & & 0.180 \\
\hline Positive (+) & 32 & 45 & \\
\hline Negative (-) & 8 & 5 & \\
\hline AntiHCV & & & 0.260 \\
\hline Positive (+) & 1 & 0 & \\
\hline Negative (-) & 38 & 49 & \\
\hline Pathological grade & & & 0.277 \\
\hline I-II & 2 & 0 & \\
\hline II-III & 27 & 36 & \\
\hline III-IV & 11 & 14 & \\
\hline Tumor size $(\mathrm{cm})$ & & & $0.011^{\mathrm{a}}$ \\
\hline$>5$ & 24 & 16 & \\
\hline$\leq 5$ & 16 & 34 & \\
\hline Serum AFP level $(\mu \mathrm{g} / \mathrm{l})$ & & & 1.000 \\
\hline High $>400$ & 15 & 18 & \\
\hline Low $\leq 400$ & 25 & 32 & \\
\hline Recurrence & & & $0.009^{\mathrm{a}}$ \\
\hline Yes & 30 & 23 & \\
\hline No & 10 & 27 & \\
\hline
\end{tabular}

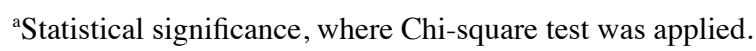

MAGE-A9 expression has higher levels in a subtype of HCCs with stem/progenitor characteristics and influences tumor sizes, recurrence and survival of HCC patients.

MAGE-A9 expression is enriched in EpCAM+ HCC cells and spheroid colonies formed by cancer stem cells. We next evaluated the expression of MAGE-A9 in $\mathrm{EpCAM}^{+}$and EpCAM cells, which were sorted from Hep3B and Huh-7 HCC cells using EpCAM-FITC antibody. We found that MAGE-A9 significantly exhibited elevated expression in $\mathrm{EpCAM}^{+}$cells compared with EpCAM cells (Fig. 2A and B). To further examine MAGE-A9 expression in LCSCs, we employed a method of serum-free suspension culture method $(28,29)$ to isolate stem-like cells from Hep3B and Huh-7 cells. As expected, the enrichment of MAGE-A9 protein occurred in spheroid colonies compared with parent cells of Hep3B and Huh-7, demonstrated by western blotting assay, respectively (Fig. 2C and D).

On the other hand, we restored the spheroid colony formed by Hep3B cells to the conventional adherent culture condition, and evaluated MAGE-A9 expression level at different culture time-points (Fig. 2E). As a result, MAGE-A9 enrichment gradually decreased when these spheroid colonies were returned into the conventional culture manner, as indicated by quantitative RT-PCR (Fig. 2F) and western blotting assay (Fig. 2G). Moreover, we also examined the expression of certain genes (AFP, cytokeratin 18 and albumin), which could reflect differentiated state of hepatic stem/progenitor and mature cells. The results showed that AFP was upregulated in the spheroid colonies and then decreased gradually upon conventional adherent culture, whereas cytokeratin 18 (Ck-18) and albumin (ALB) expression was downregulated in the spheroid colonies and subsequently restored in recovered cells (Fig. 2F and G). Collectively, the data suggest that MAGE-A9 exhibits enriched expression in liver cancer stem cells.

Effects of MAGE-A9 overexpression on cell proliferation, colony formation and cell migration. To investigate whether MAGE-A9 high-expression contributes to malignancy, we performed cell growth curve and colony formation assay to evaluate the role of MAGE-A9 in HCC cell lines, including Hep3B, Huh-7, MHCC97 and Sk-hep-1. As reported, Hep3B and Huh-7 cells are EpCAM ${ }^{+}$, while MHCC97 and Sk-hep-1 cells remain $\operatorname{EpCAM}^{-}(7,30,31)$, which was also confirmed by western blot assay (Fig. 3A). The HCC cells were transfected with lentivirus carrying flagged MAGE-A9, and western blotting assay showed that ectopic MAGE-A9 stably expressed in the four HCC cell lines (Fig. 3B). Intriguingly, MAGE-A9 overexpression led to increased growth of Hep3B and Huh-7 cells (Fig. 3C), but had no obvious effects on cell proliferation of MHCC97 and Sk-hep-1 cells (Fig. 3D). Similarly, anchorage-dependent colony formation assay showed overexpressed MAGE-A9 significantly promoted anchorage-dependent colony formation of Hep3B and Huh-7 cells (Fig. 3E), while the colony formation seems to be hardly influenced by MAGE-A9 overexpression in MHCC97 and Sk-hep-1 cells (Fig. 3F). In addition, we evaluated the effect of MAGE-A9 on cell migration using Transwell assay. The result showed that MAGE-A9 overexpression significantly promoted migration ability of Hep3B and Huh-7 cells (Fig. 3G), but had few effect on MHCC97 and Sk-hep-1 cells (Fig. 3H). Taken together, these data demonstrate that MAGE-A9 depends on the context of EpCAM expression to play its roles in promoting cell proliferation, colony formation and migration.

Effects of MAGE-A9 knockdown on HCC cell proliferation and self-renewal. Above investigations suggested that HCC cells with MAGE-A9 high expression are potential cancer stem/progenitor cells as an initiating role in tumorigenicity. To confirm that MAGE-A9 could serve as a therapeutic target, we employed lentivirus-mediated RNA interference to knock down endogenous MAGE-A9 in Hep3B and Huh-7 cells, as confirmed by qPCR and western blot analysis (Fig. 4A and B). Then, we performed anchorage-dependent colony formation 
A

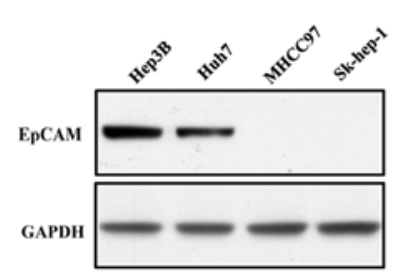

B

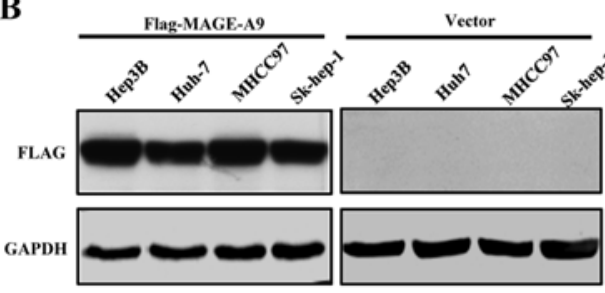

C
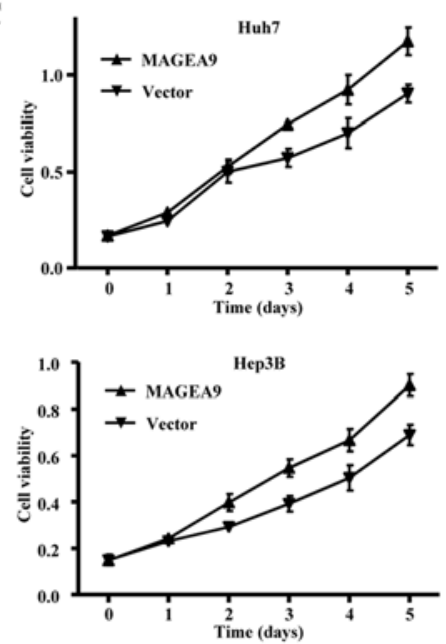

D
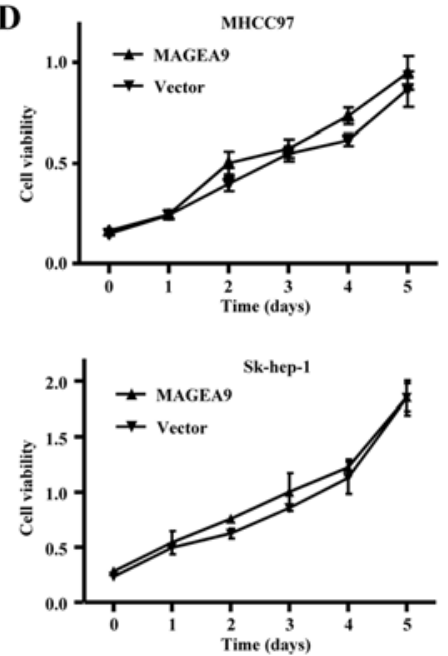

E
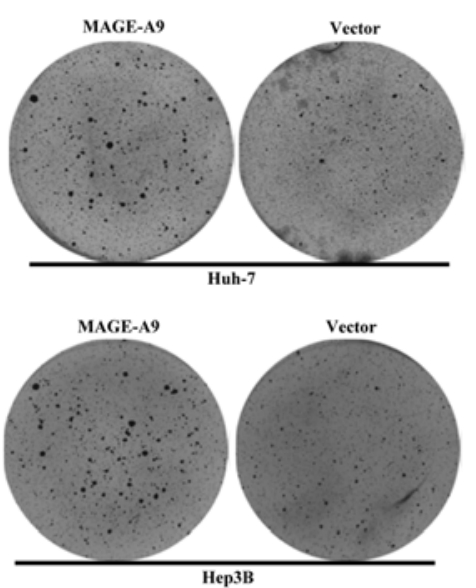

G
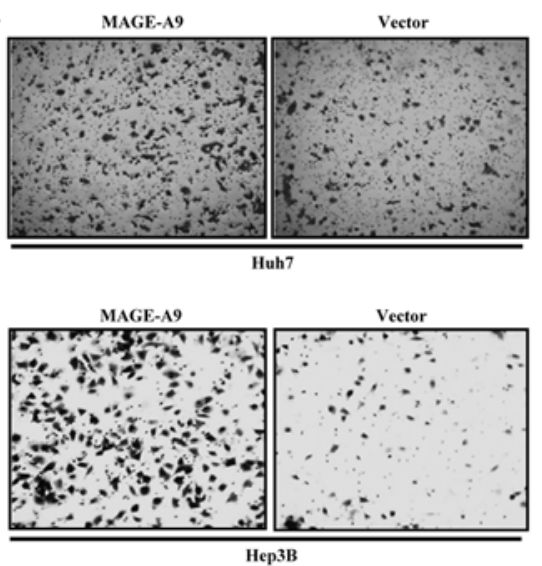
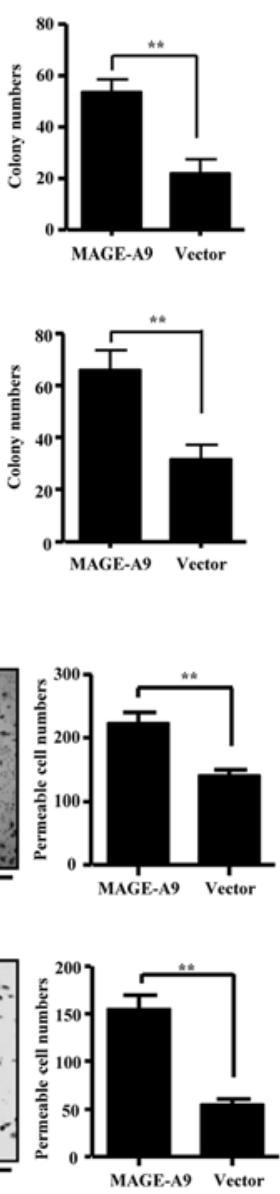

$\mathbf{F}$
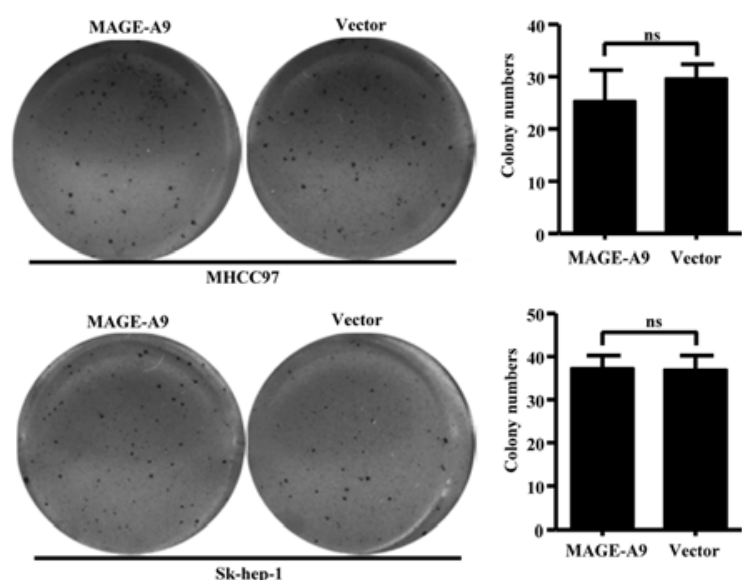

H
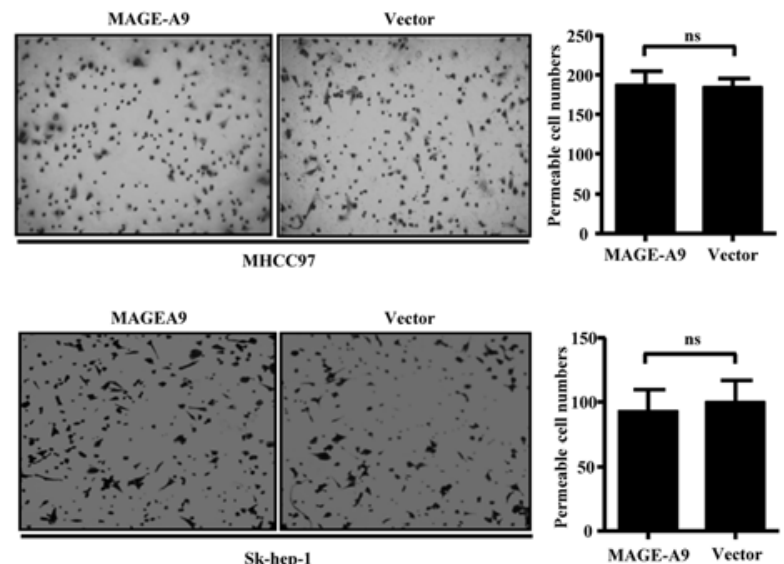

Figure 3. Effects of MAGE-A9 overexpression on cell proliferation, anchorage-dependent colony formation, and cell migration. (A) Western blot analysis of EpCAM in Hep3B, Huh-7, MHCC97 and Sk-hep-1 cells. (B) Western blotting assay with anti-FLAG antibody was performed in the four HCC cell lines with stable MAGE-A9 overexpression, where these cells infected with empty lentivirus vector were negative controls. (C) Cell growth curves were consecutively

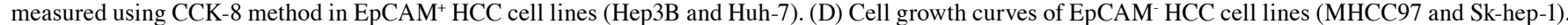
( $\mathrm{E}$ and $\mathrm{F}$ ) Anchorage-dependent colony formation assay was performed to evaluate the effect of MAGE-A9 overexpression on cell proliferation in EpCAM ${ }^{+}$ Hep3B and Huh-7 cells (E) and EpCAM- MHCC97 and Sk-hep-1 cells (F), respectively. Histograms shown on the right panel represent the mean numbers of colonies from triplicate tests (mean $\pm \mathrm{SD}$ ), and the statistical significance of difference between colony numbers was determined with two-tailed t-test. ${ }^{* *} \mathrm{P}<0.01$; ns, no significance. ( $\mathrm{G}$ and $\mathrm{H}$ ) Effect of overexpressed MAGE-A9 on cell migration was evaluated using Transwell assay in Hep3B and Huh-7 EpCAM $^{+}$cells (G) and MHCC97 and Sk-hep-1 EpCAM- cells (H), respectively. Histograms represent the mean numbers of permeable cells from triplicate tests (mean $\pm \mathrm{SD}$ ). Two-tailed t-test was used to calculate the statistical significance of these experiments.

and spheroid colony formation assays to observe the effects of MAGE-A9. As a result, MAGE-A9 knockdown significantly inhibited anchorage-dependent colony formation of HCC cell lines Hep3B and Huh-7 (Fig. 4C and D). Furthermore, the spheroid colony formation assay demonstrated that MAGE-A9 knockdown also significantly restrained spheroid colony 
$\mathbf{A}$

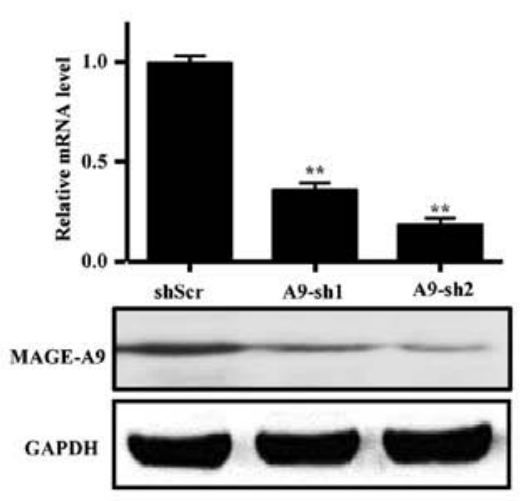

B

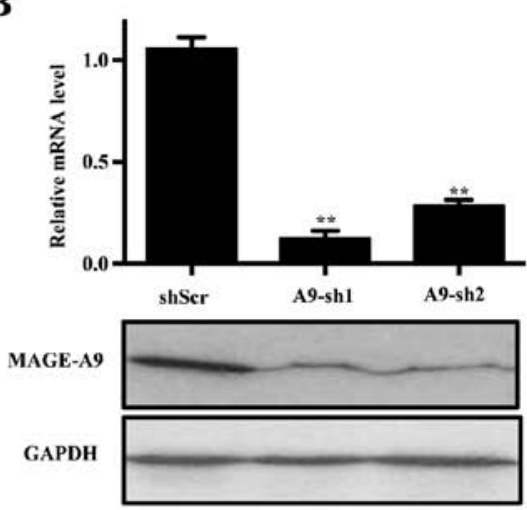

C
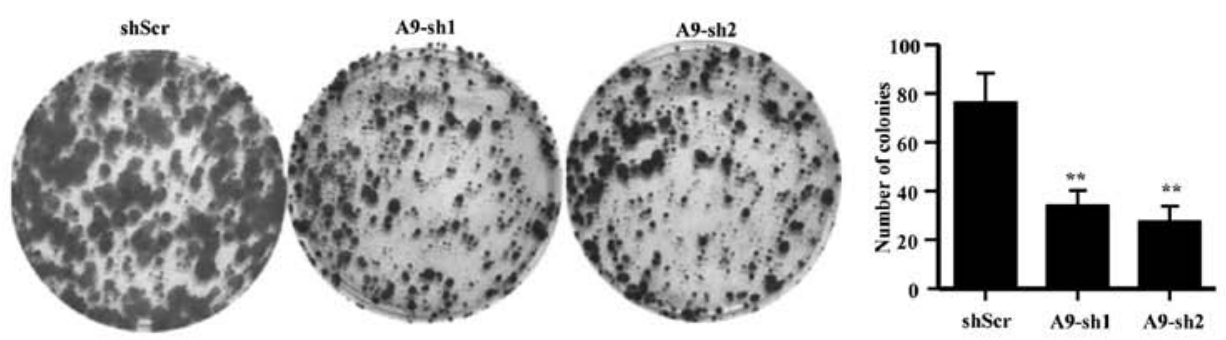

D
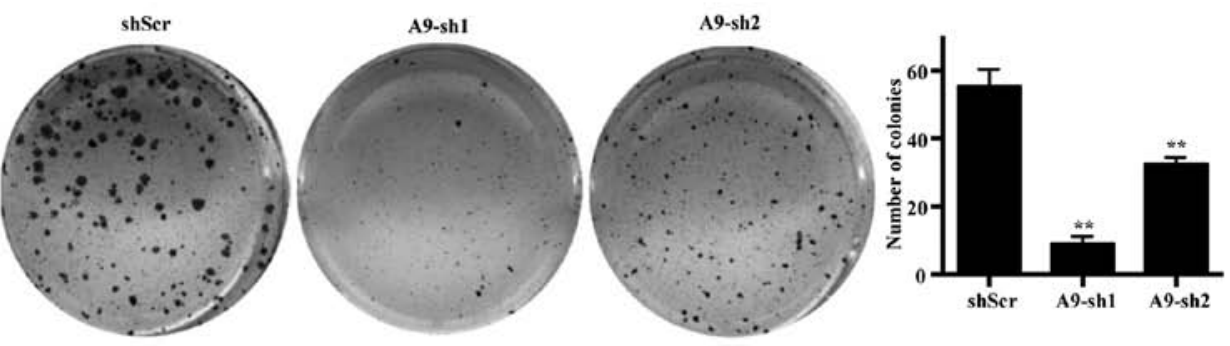

$\mathbf{E}$

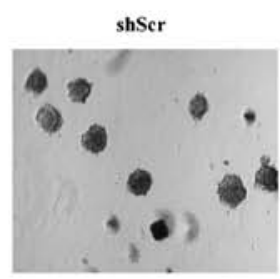

A9-sh1

A9-sh2
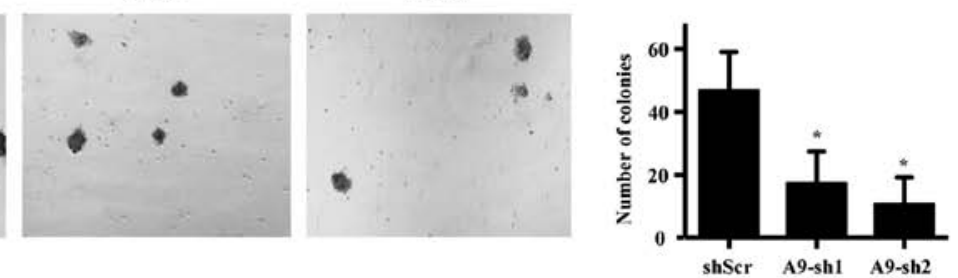

F

shSer

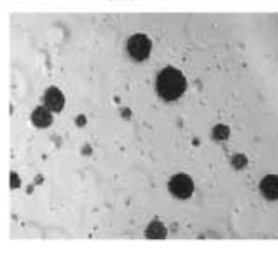

A9-sh1

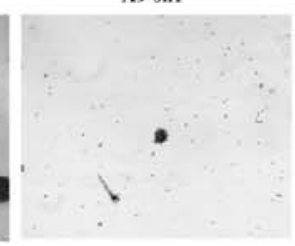

A9-sh2

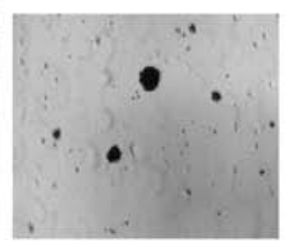

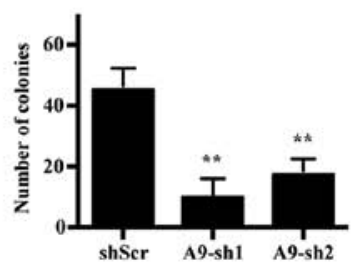

Figure 4. Anti-proliferative role of MAGE-A9 knockdown in HCC cells. (A and B) qRT-PCR analysis (upper panel) and Western blot assay (lower panel) were performed to evaluate knockdown efficiency of two shRNA against MAGE-A9 in Hep3B (A) and Huh-7 (B) HCC cells with scrambled shRNA (shScr) as a negative control. (C and D) Anchorage-dependent colony formation assay was performed to observe proliferative effects of lentivirus-mediated MAGE-A9 knockdown on Hep3B (C) and Huh-7 (D) cells. As shown in the right panel, formed colonies were counted and statistically analyzed using a two-tailed t-test. (E and F) Moreover, spheroid colony formation assay was performed in Hep3B (E) and Huh-7 (F) cells cultured in serum-free medium, upon MAGE-A9 knockdown. Numbers of colonies are shown in the right histogram and statistically analyzed using the Student's t-test. ${ }^{*} \mathrm{P}<0.05 ;^{* *} \mathrm{P}<0.01$.

formation of the two HCC cell lines (Fig. 4E and F). These data suggested that MAGE-A9, a regulator of cell proliferation and self-renewal, could serve as a potential therapeutic target against HCC.
MAGE-A9 confers chemoresistance in EpCAM+ HCC cells. As reported, cancer stem/progenitor cells are resistant to routine chemotherapy. To investigate whether MAGE-A9 could be involved in chemoresistance, we treated Hep3B and 
A

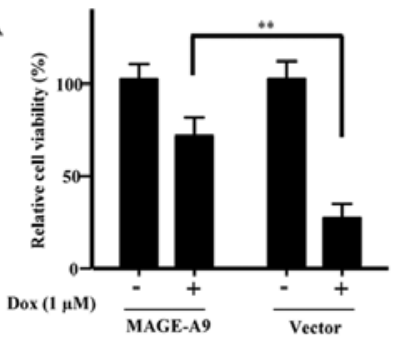

C

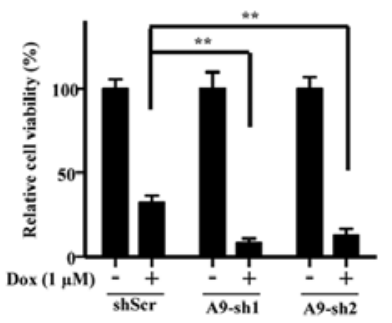

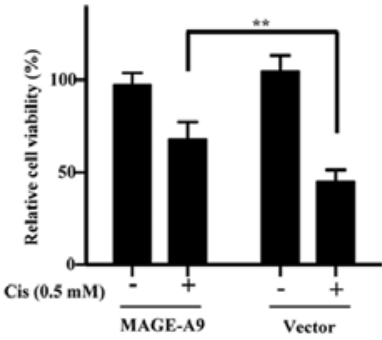

B
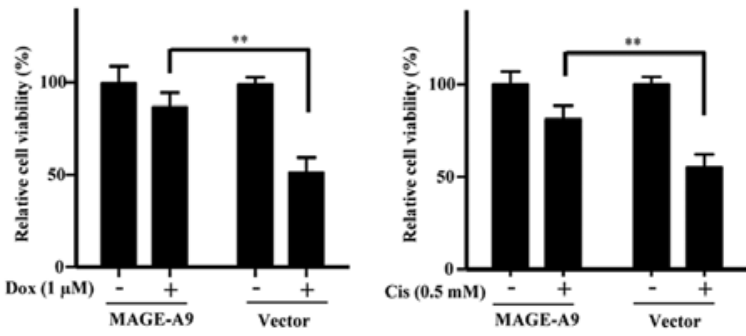

D

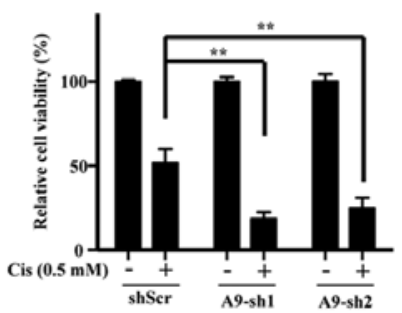

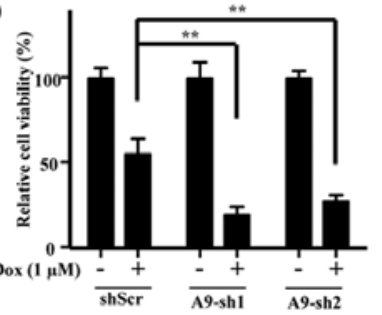

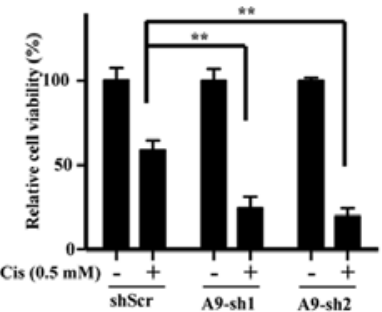

Figure 5. Effects of MAGE-A9 on chemoresistance. Chemoresistance of (A) Hep3B and (B) Huh-7 cells was raised by MAGE-A9 overexpression. In contrast, MAGE-A9 knockdown led to chemosensitization of (C) Hep3B and (D) Huh-7. These cells were treated with $1 \mu$ M doxorubicin (Dox), 0.5 mM cisplatin (Cis) for 3 days, and then cell viability was analyzed.

A

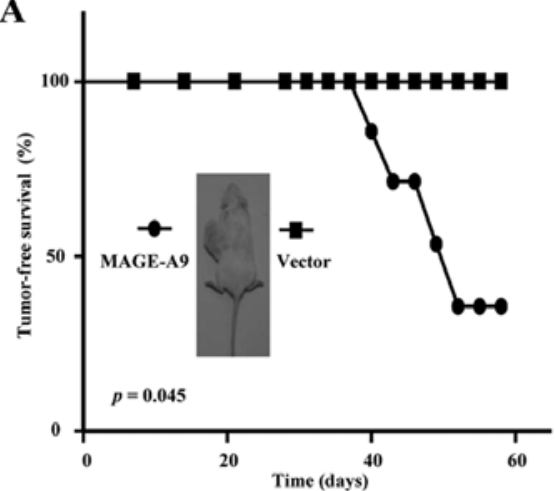

B

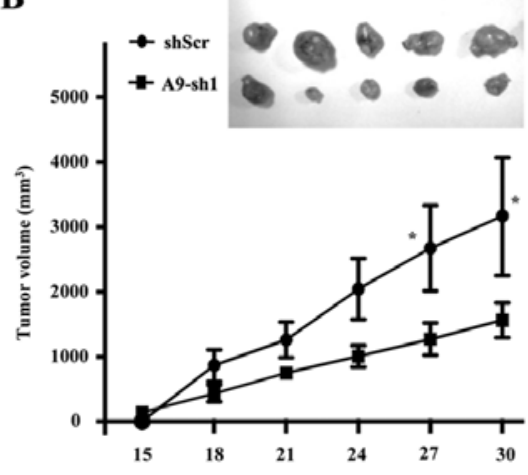

C

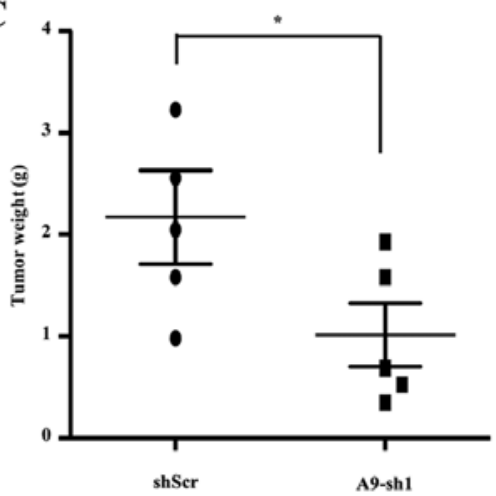

Figure 6. Effects of MAGE-A9 on tumorigenicity and tumor burden in a xenograft mouse model. (A) Hep3B cells (1x10 ${ }^{4}$ ) from spheroid culture were infected with lentivirus of MAGE-A9 and then injected subcutaneously into a single flank of NOD-SCID mice ( $\mathrm{n}=7$ ), while the same number of cells infected with pLenti-GFP vector were used as a control. Tumor-free Kaplan-Meier survival curve of these mice was statistically analyzed using a log-rank test. (B) Hep3Bformed spheroid cells $\left(2 \times 10^{5}\right)$ with infection of A9-sh1 lentivirus were subcutaneously injected into a single flank in NOD-SCID mice (n=5), while cells infected with Lenti-shScr were subcutaneously injected into opposite flanks of the same mice. Tumor size was measured by serial calibration, and tumor volume with SEM is shown. (C) Tumor weights were statistically analyzed using the paired Student's t-test. "P<0.05.

Huh-7 cells with two kinds of common chemotherapeutic drugs: doxorubicin and cisplatin, when MAGE-A9 was overexpressed and knocked down, respectively. Notably, MAGE-A9 overexpression enhanced chemoresistance to doxorubicin and cisplatin in the two EpCAM ${ }^{+} \mathrm{HCC}$ cell lines Hep3B and Huh-7 (Fig. 5A and B). On the contrary, MAGE-A9 knockdown promoted chemosensitivity to the two drugs in Hep3B cells (Fig. 5C). Moreover, similar results were observed in Huh-7 cells (Fig. 5D). Taken together, these data suggest that MAGE-A9 plays a vital role in the chemoresistance of $\mathrm{EpCAM}^{+} \mathrm{HCC}$.

Effects of MAGE-A9 on tumorigenicity of CSC-like HCC cells. To further evaluate the role of MAGE-A9 in LCSCs, we dissociated these Hep3B-formed spheroid cells with trypsin digestion into single cell suspension. Following cell counting,
$1 \times 10^{4}$ cells with lentivirus infection of MAGE-A9 were subcutaneously injected into the flank of NOD/SCID mice, and an equal volume of cells with Lenti-GFP vector as controls, were injected into the opposite flank of the same mice. Intriguingly, Hep3B spheroid cells with MAGE-A9 overexpression significantly resulted in the occurrence of visible tumors from spheroid Hep3B cells over 2 months. Kaplan-Meier tumorfree survival analysis showed that MAGE-A9 overexpression significantly promoted tumorigenesis $(\mathrm{P}<0.05$; Fig. 6A). In addition, $2 \times 10^{5} \mathrm{Hep} 3 \mathrm{~B}$-formed spheroid cells were infected with lentivirus of A9-sh1 and then subcutaneously inoculated into the flanks of NOD/SCID mice. Expectedly, MAGE-A9 knockdown significantly suppressed the tumorigenesis of these spheroid cells, with the size and weight of the xenograft tumors reduced (Fig. 6B and $\mathrm{C}$ ). In conclusion, the data showed that MAGE-A9 could be a key driver of HCC initiation and serve 
as a potential therapeutic target, probably through targeting LCSCs.

\section{Discussion}

In the present study, we showed that MAGE-A9 had enriched expression in a subtype of HCC which had features of hepatic stem/progenitor cells. Although MAGE-A9 has been reported to have high expression and significant associations with the development and prognosis of human cancers, including lung, liver, ovarian, colon, breast, renal and liver cancers $(18,19,21-24,26,32-34)$, few studies have involved its role in cancer stem cells. In line with a previous report (24), our analysis of MAGE-A9 expression in a cohort of HCC patients revealed patients with MAGE-A9-high expression had a worse overall survival compared with patients with MAGE-A9-low or none-expressing tumors, supporting its predictive association with poor clinical outcomes. Hepatocellular carcinomas that harbor phenotypic features of stem cells and progenitor cells constitute a subclass of therapeutically challenging cancers that are associated with a particularly poor prognosis (35). The evidence of MAGE-A9 expression and prognostic predictor strongly suggest that MAGE-A9 have important roles in liver cancer stem cells. Further functional experiments support that MAGE-A9 plays a role in regulating stemness characteristics in $\mathrm{EpCAM}^{+} \mathrm{HCC}$ cells. Since EpCAM is a wnt- $\beta$-catenin signaling target gene 30), MAGE-A9 may function in the context of the activation of $\beta$-catenin signaling.

The present study also showed that MAGE-A9 could serve as a therapeutic target against liver stem cancer cells, which highlights the need to develop a novel therapeutic approach for HCC stem or stem-like subtype. Although immunotherapy of MAGE CTAs has had little success and met challenges for many years, the development and application of CRISPR-Cas9 gene editing technique will revolutionarily pave the way to targeted-MAGE-A9 therapy against HCC. Most recently, an increasing number of reports have demonstrated that CRISPR/Cas9-mediated genome editing is a powerful technology for gene therapy $(36,37)$. The application of CRISPR/Cas9-mediated MAGE-A9 deficiency in vitro and in vivo will explore the feasibility and practicability of MAGE-A9 targeted therapy. In addition, understanding the transcriptional regulations controlling the aberrant MAGE-A9 re-expression in HCC may provide insight into potential drug targets for MAGE-A9-expressing tumors. Type I MAGEs are not normally expressed in somatic cells due to methylation of $\mathrm{CpG}$ islands in their promoter regions. Demethylating agents such as 5-aza-2-deoxycytidine (5DC) and HDAC inhibitor such as trichostatin A can induce expression of MAGE-A1 in cancer cells $(38,39)$. A similar result that MAGE-A9 was re-opened in several HCC cells treated with 5DC and trichostatin A was observed in this study (data not shown). As for detailed mechanisms proposed for the demethylation of type I MAGE promoters, some pathways may be the key to understand how type I MAGEs are turned on in cancer cells. For example, the deregulation of KIT tyrosine kinase activity and the FGFR2-IIIb that was found to be a putative upstream regulator of MAGEA3/6 expression $(40,41)$. Fibronectin knockdown also led to increased MAGE-A3 expression (42).
To date, molecular mechanism how MAGE-A9 modulate malignant characteristics of LCSCs is unclear in the present study. Increasing investigations on other MAGE genes may provide primary references for the MAGE-A9-associated mechanistic study. For instance, the MHDs of MAGE-A2, -A3, -A6 and -C2 can bind to the coiled-coil domain of the TRIM28/ KAP1 ubiquitin ligase $(43,44)$. Importantly, identification of MAGE-A9-mediated signaling transduction and molecular interaction will possibly unveil deeper understanding of the molecular pathogenesis of HCC. A typical example is the finding that MAGE-A3-TRIM28 and MAGE-A6-TRIM28 ligase complexes can ubiquitinate the alpha catalytic subunit (PRKAA1) of the tumor suppressor AMPK, leading to AMPK degradation and reduction of overall AMPK protein levels in tumors (45-47). Because AMPK agonists (e.g. metformin) and mTOR inhibitors (e.g. everolimus) are already in use in the clinic (48), the utilization of MAGE-A3 and -A6 may act as a biomarkers for effective use of these drugs (45). Taken together, our data suggest that MAGE-A9 exhibits enrichment expression in liver cancer stem/progenitor cells and could be a potential therapeutic target against liver cancer. Although these findings provided a basic perspective of cancer testis antigens in liver cancer stem cells, further investigations are still needed in the future.

\section{Acknowledgements}

The present study was supported by the National Natural Science Foundation of China (no. 81660350), the Jiangxi Provincial Department of Science and Technology (no. 20161BBH80001) and the Health and Family Planning Commission of Jiangxi Province (nos. 20164013, 20177026 and 20174004).

\section{References}

1. Nio K, Yamashita T and Kaneko S: The evolving concept of liver cancer stem cells. Mol Cancer 16: 4, 2017.

2. Zhu CP, Wang AQ, Zhang HH, Wan XS, Yang XB, Chen SG and Zhao HT: Research progress and prospects of markers for liver cancer stem cells. World J Gastroenterol 21: 12190-12196, 2015.

3. Lee TK, Cheung VC and Ng IO: Liver tumor-initiating cells as a therapeutic target for hepatocellular carcinoma. Cancer Lett 338: 101-109, 2013.

4. Liu LL, Fu D, Ma Y and Shen XZ: The power and the promise of liver cancer stem cell markers. Stem Cells Dev 20: 2023-2030, 2011.

5. Salnikov AV, Kusumawidjaja G, Rausch V, Bruns H, Gross W, Khamidjanov A, Ryschich E, Gebhard MM, Moldenhauer G, Büchler MW, et al: Cancer stem cell marker expression in hepatocellular carcinoma and liver metastases is not sufficient as single prognostic parameter. Cancer Lett 275: 185-193, 2009.

6. Dollé L, Theise ND, Schmelzer E, Boulter L, Gires O and van Grunsven LA: EpCAM and the biology of hepatic stem/ progenitor cells. Am J Physiol Gastrointest Liver Physiol 308: G233-G250, 2015.

7. Yamashita T, Ji J, Budhu A, Forgues M, Yang W, Wang HY, Jia H, Ye Q, Qin LX, Wauthier E, et al: EpCAM-positive hepatocellular carcinoma cells are tumor-initiating cells with stem/progenitor cell features. Gastroenterology 136: 1012-1024, 2009.

8. Simpson AJ, Caballero OL, Jungbluth A, Chen YT and Old LJ: Cancer/testis antigens, gametogenesis and cancer. Nat Rev Cancer 5: 615-625, 2005.

9. Cronwright G, Le Blanc K, Götherström C, Darcy P, Ehnman M and Brodin B: Cancer/testis antigen expression in human mesenchymal stem cells: Down-regulation of SSX impairs cell migration and matrix metalloproteinase 2 expression. Cancer Res 65: 2207-2215, 2005. 
10. Saldanha-Araujo F, Haddad R, Zanette DL, De Araujo AG, Orellana MD, Covas DT, Zago MA and Panepucci RA: Cancer/ Testis antigen expression on mesenchymal stem cells isolated from different tissues. Anticancer Res 30: 5023-5027, 2010

11. Wen J, Li H, Tao W, Savoldo B, Foglesong JA, King LC, Zu Y and Chang CC: High throughput quantitative reverse transcription PCR assays revealing over-expression of cancer testis antigen genes in multiple myeloma stem cell-like side population cells. Br J Haematol 166: 711-719, 2014.

12. Yin B, Zeng Y, Liu G, Wang X, Wang P and Song Y: MAGE-A3 is highly expressed in a cancer stem cell-like side population of bladder cancer cells. Int J Clin Exp Pathol 7: 2934-2941, 2014.

13. Yamada R, Takahashi A, Torigoe T, Morita R, Tamura Y, Tsukahara T, Kanaseki T, Kubo T, Watarai K, Kondo T, et al: Preferential expression of cancer/testis genes in cancer stem-like cells: Proposal of a novel sub-category, cancer/testis/stem gene. Tissue Antigens 81: 428-434, 2013.

14. Soulez M, Saurin AJ, Freemont PS and Knight JC: SSX and the synovial-sarcoma-specific chimaeric protein SYT-SSX co-localize with the human Polycomb group complex. Oncogene 18: 2739-2746, 1999.

15. Weon JL and Potts PR: The MAGE protein family and cancer. Curr Opin Cell Biol 37: 1-8, 2015

16. Jia HL, Ye QH, Qin LX, Budhu A, Forgues M, Chen Y, Liu YK, Sun HC, Wang L, Lu HZ, et al: Gene expression profiling reveals potential biomarkers of human hepatocellular carcinoma. Clin Cancer Res: an official journal of the American Association for Cancer Research 13: 1133-1139, 2007. https://doi org/10.1158/1078-0432.CCR-06-1025.

17. Picard V, Bergeron A, Larue $\mathrm{H}$ and Fradet Y: MAGE-A9 mRNA and protein expression in bladder cancer. Int J Cancer 120: 2170-2177, 2007

18. Bergeron A, Picard V, LaRue H, Harel F, Hovington H, Lacombe L and Fradet Y: High frequency of MAGE-A4 and MAGE-A9 expression in high-risk bladder cancer. Int J Cancer 125: 1365-1371, 2009.

19. Xu X, Tang X, Lu M, Tang Q, Zhang H, Zhu H, Xu N, Zhang D, Xiong L, Mao Y, et al: Overexpression of MAGE-A9 predicts unfavorable outcome in breast cancer. Exp Mol Pathol 97: 579-584, 2014.

20. Hou SY, Sang MX, Geng CZ, Liu WH, Lü WH, Xu YY and Shan BE: Expressions of MAGE-A9 and MAGE-A11 in breast cancer and their expression mechanism. Arch Med Res 45: 44-51, 2014.

21. Zhang S, Zhai X, Wang G, Feng J, Zhu H, Xu L, Mao G and Huang J: High expression of MAGE-A9 in tumor and stromal cells of non-small cell lung cancer was correlated with patient poor survival. Int J Clin Exp Pathol 8: 541-550, 2015.

22. Han L, Jiang B, Wu H, Zhang S and Lu X: Expression and prognostic value of MAGE-A9 in laryngeal squamous cell carcinoma. Int J Clin Exp Pathol 7: 6734-6742, 2014.

23. Hatiboglu G, Pritsch M, Macher-Goeppinger S, Zöller M, Huber J, Haferkamp A, Pahernik S, Wagener N and Hohenfellner M: Prognostic value of melanoma-associated antigen A9 in renal cell carcinoma. Scand J Urol 47: 311-322, 2013.

24. Gu X, Fu M, Ge Z, Zhan F, Ding Y, Ni H, Zhang W, Zhu Y, Tang X, Xiong L, et al: High expression of MAGE-A9 correlates with unfavorable survival in hepatocellular carcinoma. Sci Rep 4: 6625, 2014.

25. van Duin M, Broyl A, de Knegt Y, Goldschmidt H, Richardson PG, Hop WC, van der Holt B, Joseph-Pietras D, Mulligan G, Neuwirth R, et al: Cancer testis antigens in newly diagnosed and relapse multiple myeloma: Prognostic markers and potential targets for immunotherapy. Haematologica 96: 1662-1669, 2011.

26. Xu Y, Wang C, Zhang Y, Jia L and Huang J: Overexpression of MAGE-A9 is predictive of poor prognosis in epithelial ovarian cancer. Sci Rep 5: 12104, 2015.

27. Yamashita T, Forgues M, Wang W, Kim JW, Ye Q, Jia H Budhu A, Zanetti KA, Chen Y, Qin LX, et al: EpCAM and alpha-fetoprotein expression defines novel prognostic subtypes of hepatocellular carcinoma. Cancer Res 68: 1451-1461, 2008.
28. Yue W, Jiao F, Liu B, You J and Zhou Q: Enrichment and function research of large cell lung cancer stem cell-like cells. Zhongguo Fei Ai Za Zhi 14: 484-491, 2011 (In Chinese).

29. Yoshida S, Shimmura S, Shimazaki J, Shinozaki N and Tsubota K: Serum-free spheroid culture of mouse corneal keratocytes. Invest Ophthalmol Vis Sci 46: 1653-1658, 2005.

30. Yamashita T, Budhu A, Forgues M and Wang XW: Activation of hepatic stem cell marker EpCAM by Wnt-beta-catenin signaling in hepatocellular carcinoma. Cancer Res 67: 10831-10839, 2007.

31. Kimura O, Takahashi T, Ishii N, Inoue Y, Ueno Y, Kogure T, Fukushima K, Shiina M, Yamagiwa Y, Kondo Y, et al: Characterization of the epithelial cell adhesion molecule $(\mathrm{EpCAM})^{+}$cell population in hepatocellular carcinoma cell lines. Cancer Sci 101: 2145-2155, 2010.

32. Zhan W, Zhang Z, Zhang Y, Ma J, Wu T, Gu Y, Li Y and Yang J: Prognostic value of MAGE-A9 expression in patients with colorectal cancer. Clin Res Hepatol Gastroenterol 40: 239-245, 2016.

33. Zhai X, Xu L, Zhang S, Zhu H, Mao G and Huang J: High expression levels of MAGE-A9 are correlated with unfavorable survival in lung adenocarcinoma. Oncotarget 7: 4871-4881, 2016.

34. Liu S, Sang M, Xu Y, Gu L, Liu F and Shan B: Expression of MAGE-A1, -A9, -A11 in laryngeal squamous cell carcinoma and their prognostic significance: A retrospective clinical study. Acta Otolaryngol 136: 506-513, 2016.

35. Thorgeirsson SS: Stemness in liver cancer. Dig Dis 35: 387-389, 2017.

36. Zhang X, Wang L, Liu M and Li D: CRISPR/Cas9 system: A powerful technology for in vivo and ex vivo gene therapy. Sci China Life Sci 60: 468-475, 2017.

37. Sachdeva M, Sachdeva N, Pal M, Gupta N, Khan IA, Majumdar M and Tiwari A: CRISPR/Cas9: Molecular tool for gene therapy to target genome and epigenome in the treatment of lung cancer. Cancer Gene Ther 22: 509-517, 2015.

38. Schwarzenbach H, Eichelser C, Steinbach B, Tadewaldt J, Pantel K, Lobanenkov V and Loukinov D: Differential regulation of MAGE-A1 promoter activity by BORIS and Sp1, both interacting with the TATA binding protein. BMC Cancer 14: 796, 2014.

39. Wischnewski F, Pantel K and Schwarzenbach H: Promoter demethylation and histone acetylation mediate gene expression of MAGE-A1, -A2, -A3, and -A12 in human cancer cells. Mol Cancer Res 4: 339-349, 2006.

40. Yang B, Wu J, Maddodi N, Ma Y, Setaluri V and Longley BJ: Epigenetic control of MAGE gene expression by the KIT tyrosine kinase. J Invest Dermatol 127: 2123-2128, 2007.

41. Kondo T, Zhu X, Asa SL and Ezzat S: The cancer/testis antigen melanoma-associated antigen-A3/A6 is a novel target of fibroblast growth factor receptor 2-IIIb through histone H3 modifications in thyroid cancer. Clin Cancer Res 13: 4713-4720, 2007.

42. Liu W, Cheng S, Asa SL and Ezzat S: The melanoma-associated antigen A3 mediates fibronectin-controlled cancer progression and metastasis. Cancer Res 68: 8104-8112, 2008.

43. Doyle JM, Gao J, Wang J, Yang M and Potts PR: MAGE-RING protein complexes comprise a family of E3 ubiquitin ligases. Mol Cell 39: 963-974, 2010.

44. Yang B, O'Herrin SM, Wu J, Reagan-Shaw S, Ma Y, Bhat KM, Gravekamp C, Setaluri V, Peters N, Hoffmann FM, et al: MAGE-A, mMage-B, and MAGE-C proteins form complexes with KAP1 and suppress p53-dependent apoptosis in MAGEpositive cell lines. Cancer Res 67: 9954-9962, 2007.

45. Pineda CT, Ramanathan S, Fon Tacer K, Weon JL, Potts MB, Ou YH, White MA and Potts PR: Degradation of AMPK by a cancer-specific ubiquitin ligase. Cell 160: 715-728, 2015.

46. Hardie DG: Molecular pathways: Is AMPK a friend or a foe in cancer? Clin Cancer Res 21: 3836-3840, 2015.

47. Choudhury Y, Salt IP and Leung HY: AMPK-friend or foe for targeted therapy? Cell Cycle 14: 1761-1762, 2015

48. Kasznicki J, Sliwinska A and Drzewoski J: Metformin in cancer prevention and therapy. Ann Transl Med 2: 57, 2014. 